\title{
Triatominae (Hemiptera, Reduviidae) in the Pantanal region: association with Trypanosoma cruzi, different habitats and vertebrate hosts
}

\author{
Filipe Martins Santos ${ }^{[1]}$, Ana Maria Jansen ${ }^{[2]}$, Guilherme de Miranda Mourão ${ }^{[3]}$, \\ José Jurberg ${ }^{[4]}$, Alessandro Pacheco Nunes ${ }^{[5]}$ and Heitor Miraglia Herrera ${ }^{[1]}$
}

\begin{abstract}
[1]. Laboratório de Parasitologia Animal, Universidade Católica Dom Bosco, Campo Grande, Mato Grosso do Sul, Brazil. [2]. Laboratório de Biologia de Tripanossomatídeos, Instituto Oswaldo Cruz, Fundação Oswaldo Cruz, Rio de Janeiro, Brazil. [3]. Laboratório de Vida Selvagem, Centro de Pesquisa Agropecuária do Pantanal/Embrapa-Pantanal, Corumbá, Mato Grosso do Sul, Brazil. [4]. Laboratório Nacional e Internacional de Referência em Taxonomia de Triatomíneos, Instituto Oswaldo Cruz, Fundação Oswaldo Cruz, Rio de Janeiro, Brazil. [5]. Programa de Pós-Graduação em Ecologia e Conservação, Universidade Federal de Mato Grosso do Sul, Campo Grande, Mato Grosso do Sul, Brazil.
\end{abstract}

ABSTRACT

Introduction: The transmission cycle of Trypanosoma cruzi in the Brazilian Pantanal region has been studied during the last decade. Although considerable knowledge is available regarding the mammalian hosts infected by T. cruzi in this wetland, no studies have investigated its vectors in this region. This study aimed to investigate the presence of sylvatic triatomine species in different habitats of the Brazilian Pantanal region and to correlate their presence with the occurrences of vertebrate hosts and T. cruzi infection. Methods: The fieldwork involved passive search by using light traps and Noireau traps and active search by visual inspection. The light traps were placed at five selected points along forested areas for seven nights during each of the nine excursions. At each point where a light trap was set, eight Noireau traps were placed in palm trees and bromeliads. Results: In all, 88 triatomine bugs were collected: two and one individuals from light traps and Noireau traps, respectively; three from peridomestic areas; 23 in coati nests; and 59 in thornbird nests. In this study, active search in microhabitats showed higher efficiency than passive search, since $95 \%$ of the triatomine bugs were caught in nests. Further, triatomine bugs were only found to be infected by T. cruzi in coati nests. Conclusions: Coati nests might act as a point of convergence and dispersion for triatomine bugs and mammal hosts infected by T. cruzi, thereby playing an important role in the sylvatic cycle of T. cruzi in the Pantanal region.

Keywords: Host-parasite relationship. Nasua nasua. Phacellodomus sp. Triatominae. Wetlands.

\section{INTRODUCTION}

The Triatominae (Hemiptera, Reduviidae) currently include 148 species and 18 genera $^{(1)(2)}$. These species belonging to this subfamily can act as invertebrate hosts for Trypanosoma cruzi (Protozoa, Kinetoplastida, Trypanosomatidae), the important digenetic parasite of Chagas disease (CD). The life cycle of T. cruzi is enzootic to a large region extending from Patagonian Argentina to southern Texas; currently, 12 million people are estimated to be infected with this protozoon, and 60 million people live in areas at risk of CD worldwide ${ }^{(3)}$.

Triatomine bugs exclusively include blood-sucking insects. This behavior is exhibited at any stage of life and by both the sexes ${ }^{(1)}$. In the absence of vertebrates, triatomines might

Corresponding author: Dr. Heitor Miraglia Herrera. Laboratório de Parasitologia Animal/UCDB. Av. Tamandaré 6000, Jardim Seminário, 79117-900 Campo Grande, Mato Grosso do Sul, Brasil.

Phone: 5567 9962-5212

e-mail: herrera@ucdb.com; filipemsantos@outlook.com

Received 8 June 2015

Accepted 19 August 2015 feed on the hemolymph of other invertebrates ${ }^{(1)}$. The classical transmission of T. cruzi occurs through contamination of feces by epimastigote forms of $T$. cruzi at the time when triatomine bugs are feeding on blood of parasitic hosts ${ }^{(1)}$. T. cruzi is also transmitted via the oral route into the sylvatic environment, and this mechanism of transmission has been considered responsible for the recent outbreaks of $\mathrm{CD}^{(4)(5)(6)}$. The remarkable diversity of wild triatomine bugs, along with constant anthropogenic changes in the natural environment, might favor contact between humans and free-roaming bugs, thus leading to T. cruzi infection $^{(7)}$.

Several triatomine bugs maintain enzootic $T$. cruzi in the wild, and the spatial distribution of different triatomine bugs has been shown to be correlated with the availability of food resources and shelter in the natural environment ${ }^{(1)}$. That is, Cavernicola pilosa are mainly found in caves that harbor bats, and Panstrongylus geniculatus are found in areas with armadillos and in their underground shelters. The southern tamandua (Tamandua tetradactyla) has been reported to be infected with T. cruzi owing to its close association with Rhodnius robustus in the Brazilian Amazon region ${ }^{(8)(9)}$. Moreover, several triatomine species such as Rhodnius neglectus, Triatoma plantensis, T. sordida, Psammolestes arthuri, Psammolestes coreodes and 
Psammolestes tertius are found in bird nests, although birds are refractory to infection by T. $\mathrm{cruzi}^{(1)(10)(11)}$.

Trypanosoma cruzi is a multi-host parasite and infects mammals belonging to different orders such Chiroptera, Primates, Rodentia, Artiodactyla, Marsupialia, Cingulata, Pilosa, and Carnivora ${ }^{(9)(11)(12)}$. The enzootic cycle of T. cruzi in relation to mammalian hosts in the Pantanal region has been extensively investigated over the last decade. In fact, $T$. cruzi infection in this wetland has been reported in small mammals (rodents and marsupials), carnivores (coatis, crab-eating fox, crab-eating raccoon and ocelot), bats, armadillos, peccaries and feral pigs ${ }^{(12)(13)(14)(15)(16)(17)}$.

Although described as a single species, T. cruzi population is known to be genetically diverse. At present, there is a consensus that $T$. cruzi strains encompass six discrete typing units (DTUs): Trypanosoma cruzi I (TcI) to Trypanosoma cruzi VI (TcVI). Furthermore, the new TcBat genotype was recently described, which is restricted to bats ${ }^{(18)(19)}$. Moreover, Lima et al. ${ }^{(20)}$ found wide genetic variation among $\mathrm{TcI}$ isolates in the different biomes of Brazil. Thus, the sylvatic cycles of T. cruzi can be considered to be unpredictable and multivariable complex systems that varyingly interact with different host species (mammals and triatomine bugs), leading to the genetic plasticity of $T$. cruzi. In the Pantanal region, coatis were found to be naturally infected with several subpopulations of $T$. cruzi ${ }^{(15)}$.

Although not many species are endemic to the Pantanal region, compared with the species abundance at Atlantic Forest and Brazilian Cerrado, the biodiversity of Pantanal region is considerably high $^{(21)}$. In this biome, coatis inhabit various habitats, from the ground to treetops, connecting different T. cruzi cycles ${ }^{(16)}$. At present, knowledge regarding the diversity of triatomine bugs in the Pantanal wetland is lacking. Different bug species might be acting within different $T$. cruzi transmission cycles, which may or may not be connected.

This study aimed to investigate the presence of sylvatic triatomine bugs in different habitats and to correlate their presence with vertebrate hosts of $T$. cruzi. Further, we determined the parasitological prevalence of $T$. cruzi infection in invertebrate hosts in the Brazilian Pantanal region.

\section{METHODS}

\section{Study area}

The Pantanal is a large Neotropical wetland located in the center of South America. The climate is marked by two distinct seasons: a warm rainy period (October to March) and a cold dry period (April to September).

The fieldwork was conducted in the Southern Pantanal region, an area that has been described as having active T. cruzi transmission cycles in the last decade ${ }^{(12)(13)(14)(15)(16)(17)}$. The investigation sites included (a) Nhumirim Ranch (NHUR), $18^{\circ} 59^{\prime} 17.07^{\prime \prime} \mathrm{S} 56^{\circ} 37^{\prime} 8.65^{\prime \prime} \mathrm{W}$, which is a research station belonging to Embrapa Pantanal, along with neighboring farms with extensive cattle raising; and (b) sections of the MS-184 (67km) and MS-337 (30km) Park Roads (PRs). The phytophysiognomy of NHUR is characterized by (a) small elevations of continuous terrain covered by dense forested areas typical of the Cerrado o biome, locally known as cordilheiras; (b) open savanna consisting of shrubs and scattered trees flooded seasonally; and (c) seasonally flooded grasslands. The PRs are dirt roads constructed on causeways $1-2 \mathrm{~m}$ above the surrounding plains or at ground level in the high areas of floodplains. The terrain through which these highways pass is directly influenced by the rivers and tributaries that surround them: MS-184 by the Miranda and Abobral Rivers and MS-337 by the Negro River. The vegetation alongside these PRs comprises isolated trees and scrub vegetation.

\section{Collection of triatomines}

We collected data monthly between April and December 2013 through active and passive searches (light and Noireau traps). All field procedures and laboratory studies were conducted in accordance with a license granted by the Biodiversity Information and Authorization System of the Chico Mendes Institute for Biodiversity Conservation, under license number 37690-4. The present study was approved by the Ethics Committee for Animal Use of Dom Bosco Catholic University, Campo Grande, MS (under license number 12/2012).

Although small mammals have been described as hosts for $T$. cruzi in the studied area ${ }^{(13)(16)}$, their nests are difficult to detect due to the lack of knowledge of their biology. Moreover, nests of small mammals are very small and found in burrow tunnels in the ground, natural cavities in trees, and high in trees out of leaves (22) (23). Thus, we used light traps to catch adult triatomines that use these habitats. The traps were divided into three compartments: (a) a light source consisting of a lamp with a light-emitting diode (LED) light bulb connected to a $12 \mathrm{~V}$ battery; (b) a flap to intercept the flight of insects attracted by the light; and (c) a container for storing the insects. The light traps were set between 6:00pm and 6:00am on nights with a new moon. Two light traps were placed at each of the five selected sites along the cordilheiras in NHUR for seven nights, during each of the nine excursions.

At each point where a light trap was set, eight Noireau traps were placed in the following microhabitats: palm trees (Attalea phalerata) and bromeliads (Bromelia balansae). These traps followed the model proposed by Noireau et al. ${ }^{(24)}$. For each trap, one mouse was used as live bait. Sawdust and food were placed together with the mouse on each bug-catching night. In all, 40 Noireau traps were used on each night, placed in the late afternoon, and left there between 6:00pm and 6:00am.

We also searched for triatomines by using active searches in the peridomestic areas (around human dwellings, especially animal enclosures) and in arboreal nests that have been described as habitats of triatomine bugs ${ }^{(1)}{ }^{(2)}$ : thornbird nests (Phacellodomus sp., Funariidae, Passeriformes) along the PR (Figure 1) and nests of coatis (Nasua nasua, Procionidae, Carnivora) in the cordilheiras (Figure 2). Nests of both the species were carefully placed in plastic bags, identified, and transported to the laboratory for detecting triatomines. 

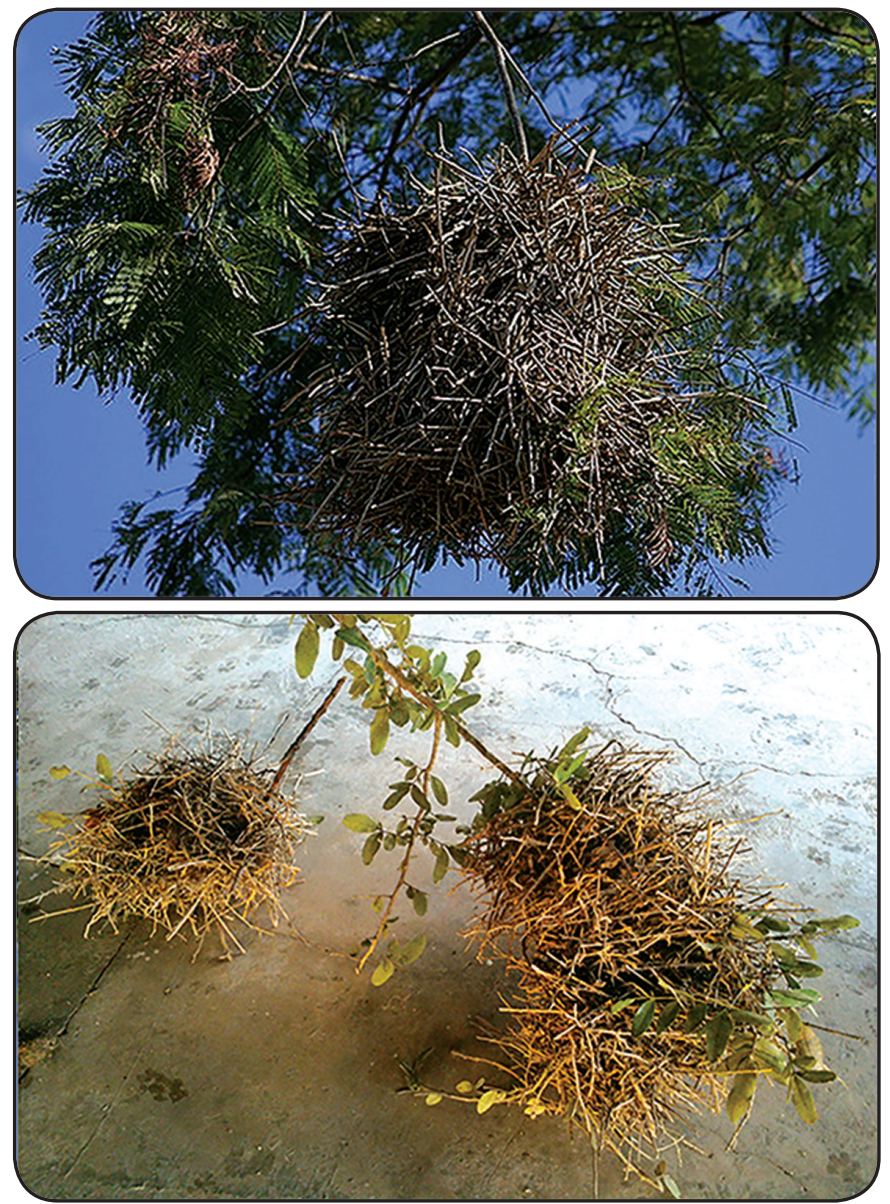

FIGURE 1 - Nests of thornbirds (Phacellodomus sp., Funariidae, Passeriformes) collected in the Southern Pantanal region of Brazil for searching for triatomines. Corumbá, State of Mato Grosso do Sul.

\section{Identification of the triatomines collected}

All triatomines collected were stored in $50-\mathrm{mL}$ Falcon tubes that were identified with the capture location and date. The triatomines were classified according to their external morphology by Dr. José Jurberg of the National and International Reference Laboratory for Triatomine Taxonomy, Oswaldo Cruz Institute [Fundação Oswaldo Cruz (FIOCRUZ), Rio de Janeiro, $\mathrm{RJ}$, by referring to the dichotomous key developed by Lent and Wygodzinsky ${ }^{(1)}$. Since the accurate morphological identification to species level is possible only with adult specimens, the immature forms collected were classified only until genus.

\section{Identification of Trypanosoma cruzi}

Parasitological tests for $T$. cruzi infection were performed at the Trypanosomatid Biology Laboratory, Oswaldo Cruz Institute, Rio de Janeiro. The intestines of live insects were examined to determine the presence of parasites. The intestinal contents were macerated with two drops of $0.85 \%$ saline solution containing antimycotics/antibiotics. A sample of the final product was then examined under an optical microscope to detect $T$. cruzi (fresh examination).

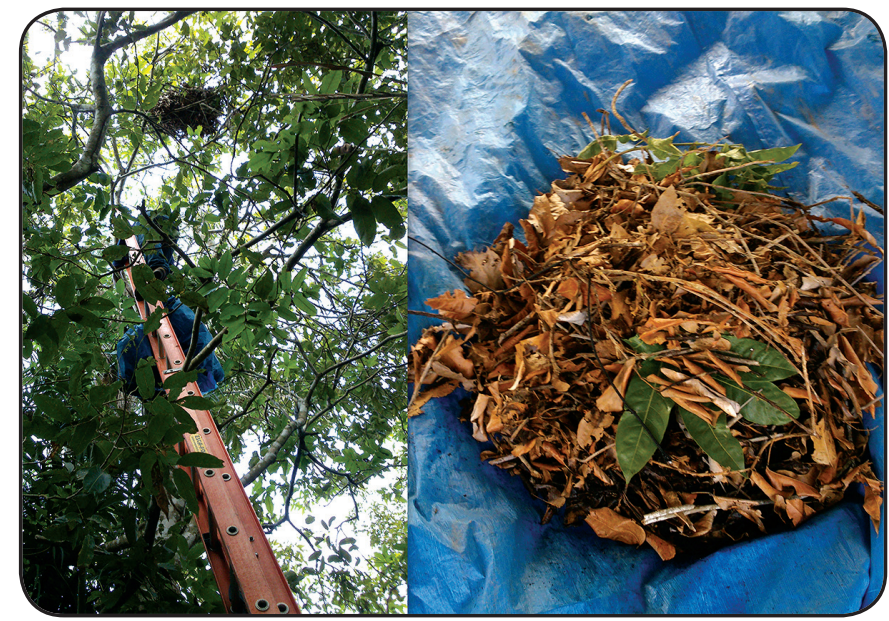

FIGURE 2 - Nests of coati (Nasua nasua) collected from the Southern Pantanal region of Brazil for searching for triatomines. Corumbá, State of Mato Grosso do Sul.

\section{RESULTS}

The capture methods used and the number of evolution stages among the triatomines collected (total, 88 specimens) are shown in Table 1. The active searches showed greater efficiency than passive searches: while only three triatomine specimens were collected using light traps $(n=2)$ and Noireau trap $(n=1)$, 85 triatomine bugs were collected by active searches.

We found that $10 \%(3 / 31)$ of coati nests inspected were colonized by triatomine bugs (one T. sordida, one Rhodnius sp., and 21 Triatoma sp.). The prevalence of $T$. cruzi in the triatomine bugs collected from a single coati nest was 70\% (16/23).

Further, $46 \%$ (11/24) of thornbird nests were colonized by triatomines. All the triatomine bugs collected were identified as Psammolestes coreodes $(n=59)$ on the basis of morphological features. The immature forms found in the thornbird nests would have been $P$. coreodes since all these individuals were collected along with P. coreodes adults. No infection by T. cruzi was observed in any of the $P$. coreodes analyzed, although small mammals, host for $T$. cruzi in the region ${ }^{(13)(16)}$, might inhabit bird nests ${ }^{(25)}$. During the active searches around dwellings, we collected triatomines from a stable (one specimen of $T$. sordida and one of Triatoma sp.) and a henhouse (one of T. sordida).

\section{DISCUSSION}

Our results showed that active searching in microhabitats, such as arboreal nests of birds and coatis, has a high degree of capture success, since this method allowed capturing $95 \%$ of the triatomine bugs. Active searching is an efficient method for collecting wild triatomines and, when the local community is evolved (which was not noted in this study), this methodology becomes even more efficient ${ }^{(26)}$. 
TABLE 1 - Species of Triatomine bugs captured with reference to different methods, evolutive stages, infection by Trypanosoma cruzi, capture effort, and capture success in the Brazilian Pantanal.

\begin{tabular}{|c|c|c|c|c|c|}
\hline Capture methods & $\begin{array}{l}\text { Triatomine } \\
\text { species }\end{array}$ & $\begin{array}{l}\text { Evolutive } \\
\text { stage }\end{array}$ & $\begin{array}{l}\text { Triatomines infected } \\
\text { by } T . \text { cruzi }\end{array}$ & $\begin{array}{c}\text { Capture } \\
\text { effort }\end{array}$ & $\begin{array}{l}\text { Capture } \\
\text { success }\end{array}$ \\
\hline Light trap & $\begin{array}{l}1 \text { Rhodnius stali } \\
1 \text { Triatoma sordida }\end{array}$ & $\begin{array}{l}\text { adult } \\
\text { adult }\end{array}$ & $\begin{array}{l}0 \\
0\end{array}$ & $7,560 \mathrm{~h}$ & $0.03^{\mathrm{a}}$ \\
\hline Noireau trap & 1 Triatoma sp. & $4^{\text {th }}$ stage nymph & 0 & $26,400 \mathrm{~h}$ & $0.004^{\mathrm{a}}$ \\
\hline Peridomestic area & $\begin{array}{c}1 \text { Triatoma sordida } \\
1 \text { Triatoma sordida } \\
1 \text { Triatoma } \mathrm{sp} .\end{array}$ & $\begin{array}{c}\text { adult } \\
\text { adult } \\
5^{\text {th }} \text { stage nymph }\end{array}$ & $\begin{array}{l}0 \\
0 \\
0\end{array}$ & 74 men & $4.1^{\mathrm{a}}$ \\
\hline Coati nest & $\begin{array}{l}1 \text { Triatoma sordida } \\
1 \text { Rhodnius } \mathrm{sp} . \\
21 \text { Triatoma } \mathrm{sp} \text {. }\end{array}$ & $\begin{array}{c}\text { adult } \\
4^{\text {th }} \text { stage nymph } \\
\text { one } 3^{\text {rd }} \text { stage nymph } \\
\text { one } 4^{\text {th }} \text { stage nymph } \\
\text { nineteen } 5^{\text {th }} \text { stage nymphs }\end{array}$ & $\begin{array}{l}0 \\
0 \\
16\end{array}$ & 31 nests & $0.74^{\mathrm{b}}$ \\
\hline Thornbird nest & 59 Psammolestes coreodes & $\begin{array}{l}\text { one } 1^{\text {st }} \text { stage nymph } \\
\text { eight } 2^{\text {nd }} \text { stage nymphs } \\
\text { ten } 3^{\text {rd }} \text { stage nymphs } \\
\text { three } 4^{\text {th }} \text { stage nymphs } \\
\text { three } 5^{\text {th }} \text { stage nymphs } \\
\quad 34 \text { adults }\end{array}$ & $\begin{array}{l}0 \\
0 \\
0 \\
0 \\
0 \\
0\end{array}$ & 24 nests & $2.46^{\mathrm{b}}$ \\
\hline
\end{tabular}

T.: Trypanosoma; ${ }^{\mathbf{a}}$ Triatomines $/ 100 \mathrm{~h} ;{ }^{\mathbf{b}}$ Triatomines/nest.

The low capture success rate by using Noireau traps in this study might have been due to the wide availability of food sources for triatomine bugs in the area studied ${ }^{(21)}$. Studies using Noireau traps for catching triatomines in biomes such as the Caatinga and Cerrado have yielded better results ${ }^{(10)(27)}$, probably because of the low abundance of food sources in these two biomes. In fact, as mentioned by Noireau et al. ${ }^{(24)}$, the capture success rate of their traps was related to the quantity of food sources and number of triatomine specimens in the ecosystem sampled.

Although many species of insects (Coleoptera, Orthoptera and Hymenoptera) are known to be attracted to light traps (personal communications), the capture success for triatomines was low by using this method. We utilized LED light bulbs because they have a longer lifespan and better electrical efficiency than incandescent bulbs; however, they do not produce heat, which is one of the main ways to attract triatomine bugs $^{(28)}$. Similar low capture success rates were reported for the municipality of Diamantina, in southeastern Brazil, where only four specimens of triatomine bugs were caught using light traps with LED light bulbs over a one-year period ${ }^{(29)}$.

The Triatoma spp. and Rhodnius spp. collected from coati nests have been described as ubiquitous sylvatic triatomine species. These triatomine bugs species are found in various natural ecotopes in the Neotropical region, from the leaves of palms, bromeliads, birds' nests, and the burrow of mammals ${ }^{(1)(4)(9)}$, and feed on different hosts species ${ }^{(1)}$. In contrast, Psammolestes coreodes found in thornbird nests has been described in close association with Phacellodomus sp., which is distributed throughout the
Southeastern region of Bolivia and Southwestern Brazil, Paraguay, and Argentina.

Nests of Phacellodomus are excellent habitats for $P$. coreodes in the southern Pantanal region, since almost half of the nests sampled were found to be colonized by triatomine species. Like other species of the genus Psammolestes, $P$. coreodes has strong ecological interactions with thornbird nests, especially Phacellodomus sp. ${ }^{(30)(31)}$. This ecological association is directly linked to the biological characteristics of the birds' nesting habits: (a) large nests, with on average two to three incubation chambers for chicks; (b) both sexes incubate the eggs and rear the nestlings; (c) formation of territories with up to ten individuals that use the nests throughout the year for sleeping, incubating their eggs, and rearing their offspring; and (d) continuous presence of newborn young birds in the territory for up to 16 months, in order to help in feeding other chicks and to use the nests again for the subsequent breeding season ${ }^{(32)}$.

The presence of a greater number of adults (58\%) of $P$. coreodes found in our study is consistent with the findings of Bar et al. ${ }^{(33)}$, who observed that $63 \%$ of the individuals present in the bird nests were adults. Likewise, Gurgel-Gonçalves and $\mathrm{Cuba}^{(31)}$ reported that $48 \%$ of the individuals in colonies of P. tertius were adults. In fact, colonies of Psammolestes sp. differ markedly from other triatomine genera because the immature stages are usually more prevalent in the colonies than adults, which generally account for less than $5 \%{ }^{(34)(35)}$. Although little information is available on the ecological aspects of $P$. coreodes, the higher proportion of triatomine adults in thornbird nests can be explained by the greater longevity and lower dispersal of 
adult bugs from the nests ${ }^{(30)}$. In addition, the long-term continual presence of Phacellodomus sp. in the nests, together with the presence of a great variety of invertebrates, would provide food supply for adult triatomines throughout the year ${ }^{(36)}$.

Besides birds, other taxa might inhabit or periodically use bird nests, and thus might serve as a food source for Psammolestes sp. ${ }^{(10)(37)}$. We found one specimen of Oecomys mamorae in one of the thornbird nests collected. Since this rodent species is arboreal and has nocturnal habits, it might be using the bird nest as a dormitory or for reproduction. Rubio and Pinho ${ }^{(25)}$ reported that $O$. mamorae use Funariidae nests for shelter and nesting in northern Pantanal region, the municipality of Poconé.

Although natural T. cruzi infection in Psammolestes spp. has not been reported, experimental studies have shown that P. coreodes and $P$. tertius might become infected with $T$. cruzi ${ }^{(1)(38)}$. Additionally, sylvatic Triatoma platensis inhabiting the nests of Phacellodomus sibilatrix were found to be naturally infected by T. cruzi in a typical area of the Chaco region of Argentina ${ }^{(39)}$. Given that natural infection by $T$. cruzi in free-living small mammals is well documented in the Pantanal region ${ }^{(13)(16)(40)}$, the presence of $O$. mamorae in thornbird nests might constitute a risk factor for P. coreodes infection by T. cruzi.

Our results showed that coati nests are colonized by triatomines of the genera Triatoma and Rhodnius. Coati nests serve as a shelter for various vertebrate and invertebrate animals ${ }^{(41)}$, which form sources of nourishment for triatomine bugs. Lima ${ }^{(42)}$ reported that triatomine bugs were found in $30 \%$ (7/23) of coati nests sampled, which was higher than that found in our study. This suggests that nest infestation with triatomine bugs might differ even within the same landscape. In our case, the result might have been influenced by particular features of the areas sampled: Lima ${ }^{(42)}$ collected samples only from the Nhumirim Ranch, which is an area with little livestock pressure $^{(43)}$, whereas our study was performed on traditional cattle-raising farms, with large densities of bovines ${ }^{(44)}$. The aggregated distribution pattern of sylvatic triatomine populations has already been reported by Suarez-Davalos et al. ${ }^{(45)}$.

Moreover, our data showed that $70 \%$ (16/23) of the triatomine bugs collected were infected by T. cruzi, similar to that reported by Alves ${ }^{(46)}(66 \% ; 16 / 23)$, who used the same triatomine bugs collected by Lima ${ }^{(42)}$. In this regard, coati nests would act as an important link in the complex cycle of T. cruzi transmission in the Pantanal region, because coatis have high levels of $T$. cruzi prevalence and parasitemias ${ }^{(15)}$ and are found together with triatomine bugs infected by $T$. cruzi in their nests. When coatis are generalists regarding their $\operatorname{diet}^{(47)}$, they become infected by $T$. cruzi by eating infected triatomine bugs, regardless of the classical vector transmission routes. Furthermore, since trans-ovarian transmission of $T$. cruzi has not been described for triatomines ${ }^{(1)}$, the immature stages of triatomine bugs present in the coati nests would become infected because of feeding on coatis infected with $T$. cruzi per occasion of nocturnal rest in nests ${ }^{(48)}$. Thus, after their development, adult triatomine bugs infected by $T$. cruzi might fly and colonize others ecological niches.
The life cycle of T. cruzi in the Pantanal wetland is complex and has a dynamic profile, because (a) T. cruzi infection has been described in a broad range of wild mammal species ${ }^{(12)(14)(15)}$, (b) some wild triatomine bug species are found in different ecological niches, (c) different subpopulations of $T$. cruzi circulate in the study area ${ }^{(15)}$, and (d) constant environmental changes through deforestation occur to implement intensive cattle farming.

\section{ACKNOWLEDGMENTS}

Universidade Católica Dom Bosco and field research staff of Nhumirim Ranch.

\section{CONFLICT OF INTEREST}

The authors declare that there is no conflict of interest.

\section{FINANCIAL SUPPORT}

Coordenação de Aperfeiçoamento de Pessoal de Nível Superior (CAPES).

\section{REFERENCES}

1. Lent H, Wygodzinsky P. Revision of the Triatominae (Hemiptera, Reduviidae) and their significance as vectors of Chagas' disease. Bull Am Mus Nat Hist 1979; 163:123-520.

2. Galvão C (organizador). Vetores da doença de chagas no Brasil. Curitiba: Sociedade Brasileira de Zoologia; 2014.

3. World Health Organization (WHO). Programmes and Projects. Fact sheets. WHO: Geneva; 2010.

4. Dias JP, Bastos C, Araújo E, Mascarenhas A, Netto E, Grassi F, et al. Acute Chagas disease outbreak associated with oral transmission. Rev Soc Bras Med Trop 2008; 41:296-300.

5. Roque AL, Xavier SC, da Rocha MG, Duarte AC, D'Andrea PS, Jansen AM. Trypanosoma cruzi transmission cycle among wild and domestic mammals in three areas of orally transmitted Chagas disease outbreaks. Am J Trop Med Hyg 2008; 79:742-749.

6. Xavier SCC, Roque ALR, Bilac D, Araújo VAL, Neto SFC, Lorosa ES, et al. Distantiae Transmission of Trypanosoma cruzi: A New Epidemiological Feature of Acute Chagas Disease in Brazil. PLoS Neg1 Trop Dis 2014; 8:1-9.

7. Klotz AS, Schmidt JO, Dorn PL, Ivanyi C, Sullivan KR, Stevens L. Free-roaming kissing bugs, vectors of Chagas disease, feed often on humans in the Southwest. Am J Med 2014; 127: 421-426.

8. Dias FB, Quartier M, Romaña CA, Diotaiuti L, Harry M. Tamandua tetradactyla Linnaeus, 1758 (Myrmecophagidae) and Rhodnius robustus Larrousse, 1927 (Triatominae) infection focus by Trypanosoma rangeli Tejera, 1920 (Trypanosomatidae) in Attalea phalerata Mart. ex Spreng (Arecaceae) palm tree in the Brazilian Amazon. Infect Genet Evol 2010; 10:1278-1281.

9. De Araújo VA, Boité MC, Cupolillo E, Jansen AM, Roque AL. Mixed infection in the anteater Tamandua tetradactyla (Mammalia: Pilosa) from Pará State, Brazil: Trypanosoma cruzi, T. rangeli and Leishmania infantum. Parasitol 2013; 140:455-460.

10. Noireau F, Carbajal De La Fuente AL, Lopes CM, Diotaiuti L. Some considerations about ecology of Triatominae. An Acad Bras Cienc 2005; 77:431-463. 
11. Noireau F, Diosque P, Jansen AM. Trypanosoma cruzi: adaptation to its vectors and its hosts. Vet Res 2009; 40:26.

12. Lisboa CV, Pinho AP, Herrera HM, Gerhardt M, Cupolillo E, Jansen AM. Trypanosoma cruzi (Kinetoplastida, Trypanosomatidae) genotypes in neotropical bats in Brazil. Vet Parasitol 2008; 156:314-318.

13. Herrera HM, Rademaker V, Abreu UG, D'andrea PS, Jansen AM. Variables that modulate the spatial distribution of Trypanosoma cruzi and Trypanosoma evansi in the Brazilian Pantanal. Acta Trop 2007; 102:55-62.

14. Herrera HM, Abreu UG, Keuroghlian A, Freitas TP, Jansen AM. The role played by sympatric collared peccary (Tayassu tajacu), white-lipped peccary (Tayassu pecari), and feral pig (Sus scrofa) as maintenance hosts for Trypanosoma evansi and Trypanosoma cruzi in a sylvatic area of Brazil. Parasitol Res 2008; 103:619-624.

15. Herrera HM, Lisboa CV, Pinho AP, Olifiers N, Bianchi RC, Rocha FL, et al. The coati (Nasua nasua, Carnivora, Procyonidae) as a reservoir host for the main lineages of Trypanosoma cruzi in the Pantanal region, Brazil. Trans R Soc Trop Med Hyg 2008; 102:1133-1139.

16. Herrera HM, Rocha FL, Lisboa CV, Rademaker V, Mourão GM, Jansen AM. Food web connections and the transmission cycles of Trypanosoma cruzi and Trypanosoma evansi (Kinetoplastida, Trypanosomatidae) in the Pantanal Region, Brazil. Trans R Soc Trop Med Hyg 2011; 105:380-387.

17. Rocha FL, Roque AL, de Lima JS, Cheida CC, Lemos FG, de Azevedo FC, et al. Trypanosoma cruzi infection in neotropical wild carnivores (Mammalia: Carnivora): at the top of the T. cruzi transmission chain. PLoS One 2013; 8:e67463.

18. Marcili A, Lima L, Cavazzana M, Junqueira AC, Veludo HH, Maia Da Silva F, et al. A new genotype of Trypanosoma cruzi associated with bats evidenced by phylogenetic analyses using SSU rDNA, cytochrome $\mathrm{b}$ and Histone H2B genes and genotyping based on ITS1 rDNA. Parasitol 2009; 136:641-655.

19. Zingales B, Miles MA, Campbell DA, Tibayrenc M, Macedo AM, Teixeira MM, et al. The revised Trypanosoma cruzi subspecific nomenclature: rationale, epidemiological relevance and research applications. Infect Genet Evol 2012; 12:240-253.

20. Lima VS, Jansen AM, Messenger LA, Miles MA, Llewellyn MS. Wild Trypanosoma cruzi I genetic diversity in Brazil suggests admixture and disturbance in parasite populations from the Atlantic Forest region. Parasi Vectors 2014; 7:263.

21. Junk WJ, Cunha CN, Wantzen KM, Petermann P, Strussmann C, Marques MI, et al. Biodiversity and its conservation in the Pantanal of Mato Grosso, Brazil. Aquat Sci 2006; 68:278-309.

22. Rossi NF. Pequenos mamíferos não-voadores do Planalto Atlântico de São Paulo: Identificação, história natural e ameaças. 2013. 400 p. (Master dissertation). Departamento de Zoologia. Instituto de Biociências. Universidade de São Paulo; 2011 São Paulo.

23. Briani DC, Vieira EM, Vieira MV. Nests and nesting sistes of Brazilian Forest rodents (Nectomys squamipes and Oryzomys intermedius) as reveales by a spool-and-line device. Acta Theriologica 2001; 46:331-334.

24. Noireau F, Abad-Franch F, Valente SAS, Dias-Lima A, Lopes CM, Cunha V, et al. Trapping Triatominae in Silvatic Habitats. Mem Inst Oswaldo Cruz 2002; 97:61-66.

25. Rubio TC, Pinho JB. Biologia reprodutiva de Synallaxis albilora (aves: Furnariidae) no Pantanal de Poconé, Mato Grosso. Pap Avulsos Zool 2008; 48:181-197.

26. Abad-Franch F, Veja MC, Rolón MS, Santos WS, Arias AR. Community Participation in Chagas Disease Vector Surveillance: Systematic Review. PLoS Negl Trop Dis 2011; 5:e1207.
27. Machiner F, Cardoso RM, Castro C, Gurgel-Gonçalves R. Occurrence of Triatoma costalimai (Hemiptera: Reduviidae) in different environments and climatic seasons: a field study in the Brazilian savanna. Rev Soc Bras Med Trop 2012; 45:567-571.

28. Lazzari CR, Núñez JA. The response to radiant heat and the estimation of the temperature of distant sources in Triatoma infestans. J Insect Physiol 1989; 35:525-529.

29. Dias JVL, Avelar BA, Cirqueira Júnior H, Diotaiuti L, Pires HHR. Capture of Triatoma arthurneivai (Hemiptera: Reduviidae) using a new luminous trap in Southeast Brazil. Rev Soc Bras Med Trop 2011; 44:774-776.

30. Silva IG, Lustosa ES. Biologia de Psammolestes tertius Lent \& Jurgberg, 1965 (Hemiptera, Reduviidae). Rev Patol Trop 1993; 22:29-42.

31. Gurgel-Gonçalves R, Cuba CAC. Infestation of Rufous-fronted thornbird nests (Passeriformes: Furnariidae) by Psammolestes tertius (Hemiptera: Reduviidae) across Brazilian Cerrado and Caatinga ecoregions. Zoologia (Curitiba) 2011; 28:411-414.

32. Carrara LA, Rodrigues M. Breeding biology of the rufousfronted thornbird Phacellodomus rufifrons, a Neotropical ovenbird. Int J Ornithol 2001; 4:209-217.

33. Bar ME, Damborsky MP, Alvarez BM, Oscherov EB, Mazza SM. Triatominos silvestres detectados en nidos de aves de algunos departamentos de la provincia de Corrientes, Argentina. Rev Soc Entomol Argent 1999; 58:43-50.

34. Diotaiuti L, Loiola CF, Falcão PL, Dias JCP. The ecology of Triatoma sordida in natural environments in two different regions of the State of Minas Gerais, Brazil. Rev Inst Med Trop Sao Paulo 1993; 35:237-245.

35. Oscherov EB, Bar ME, Damborsky MP, Milano AMF. Estadísticos poblacionales de Triatoma rubrovaria en condiciones de laboratorio. Rev Saude Publica 2005; 39:211-216.

36. Di Iorio O, Turienzo P. Insects found in birds' nests from Argentina: Coryphistera alaudina Burmeister, 1860 (Aves: Furnariidae), their inquiline birds and mammals, new hosts for Psammolestes coreodes Bergroth, 1911 and Triatoma platensis Neiva, 1913 (Hemiptera: Reduviidae: Triatominae). Zootaxa 2014; 3811:151-184.

37. Di Iorio O, Turienzo P. Insects found in birds' nests from the Neotropical Region (except Argentina) and immigrant species of Neotropical origin in the Nearctic Region. Zootaxa 2009; 2187:1-14.

38. Dias JCP. Notas sobre a biologia do Psammolestes tertius Lent \& Jurberg, 1965, no Oeste de Minas Gerais. Rev Bras Malariol e Doenç Trop 1968; 20:171-187.

39. Marti GA, Echeverria MG, Waleckx E, Susevich ML, Balsalobre A, Gorla DE. Triatominae in furnariidae nests of the Argentine Gran Chaco. J Vector Ecol 2014; 39:66-71.

40. Rademaker V, Herrera HM, Raffel TR, D'andrea OS, Freitas $\mathrm{TP}$, Abreu UG, et al. What is the role of small rodents in the transmission cycle of Trypanosoma cruzi and Trypanosoma evansi (Kinetoplastida Trypanosomatidae)? A study case in the Brazilian Pantanal. Acta Trop 2009; 111:102-107.

41. Olifiers N, Bianchi RC, Mourão GM, Gompper ME. Construction of arboreal nests by brown-nosed coatis, Nasua nasua (Carnivora: Procyonidae) in the Brazilian Pantanal. Zoologia 2009; 26:571-574.

42. Lima JS. Arboreal nests of coatis (Carnivora: Nasua nasua) in the Brazlian Pantanal: ecological and zoonotic inferences. 2013. 53p. (Master dissertation), Universidade Federal do Mato Grosso do Sul; 2013 Campo Grande.

43. Barros ATM. Dynamics of Haematobia irritans irritans (Diptera: Muscidae) Infestation on Nelore Cattle in the Pantanal, Brazil. Mem Inst Oswaldo Cruz 2001; 96: 445-450. 
44. Harris MB, Tomas W, Mourão G, Silva CJ, Guimarães E, Sonoda F, Fachim E. Safeguarding the Pantanal Wetlands: Threats and Conservation Initiatives. Conserv Biol 2005; 19:714-720.

45. Suarez-Davalos V, Dangles O, Villacis AG, Grijalva MJ. Microdistribution of Sylvatic Triatomine Populations in CentralCoastal Ecuador. J Med Entomol 2010; 47:80-88.

46. Alves FM. A complexidade, multifatoriedade e não linearidade da rede de transmissão do Tryponosoma cruzi (Trypanosomtida: Trypanosomatidae) em quatis (Carnivora: Procyonidae:
Nasua nasua) de vida livre do Pantanal/MS, um estudo longitudinal. 2013. 71p. (Master dissertation). Pós-Graduação em Medicina Tropical. Instituto Oswaldo Cruz; 2013 Rio de Janeiro.

47. Bianchi RC, Campo RC, Xavier-Filho NL, Olifiers N, Gompper $\mathrm{ME}$, Maourão G. Intraspecific, interspecific, and seasonal differences in the diet of three mid-sized carnivores in a large neotropical wetland. Acta Theriol 2014; 59:13-23.

48. Clayton J. Chagas Disease. Nature 2010; 465:4-5. 